\title{
Features of the Technology of Application of Industrial Waste in the Construction of Constructive Layers of Roadwear
}

\author{
Maxat SHANBAYEV ${ }^{*}$, Khalima TURGUMBAYEVA², Dagnija BLUMBERGA ${ }^{3}$, \\ Tuleuzhan BEYSEKOVA ${ }^{4}$ \\ ${ }^{1,2}$ Satbayev University, 22 Satpayev Str., Almaty, Republic of Kazakhstan \\ ${ }^{3}$ Institute of Energy Systems and Environment, Riga Technical University, Azenes iela 12/1, Riga, LV-1048, \\ Latvia \\ ${ }^{4}$ Al-Farabi Kazakh National University, 71 al-Farabi Ave., Almaty, Republic of Kazakhstan
}

\begin{abstract}
In this article, work was carried out to study the chemical, mineralogical composition and toxicological properties of waste (phosphogypsum, phosphorus slags, overburden) of the phosphorus industry, the optimal content of the grain composition of gravel-sand mixtures in the composition of road mixtures (crushed stone, sand-gravel, sand) and structures of the Zhambyl region of the Republic of Kazakhstan. The possibilities of using slag-mineral mixtures in the year - round construction of highways were studied on the basis of a comprehensive study of the physicochemical processes of hardening and the formation of the structure of slag-mineral materials at negative temperatures. Technological regimes for the construction of roads of various technical categories from slag binding materials, reformed after long-term freezing, have been established. New, unparalleled, binding road mixtures have been created to increase the utilization of waste from the phosphorus industry and expand the raw material base of road building materials. The main directions of application of road mixtures based on industrial waste for the purposes of road construction have been developed: construction of structural layers of road pavements; construction of road bed layers.
\end{abstract}

Keywords - Gravel-sand mixtures; granular phosphorus slag; road mixtures; slag mineral materials

\section{INTRODUCTION}

World experience shows that one of the economically and ecologically viable directions for the disposal of industrial waste is their use to obtain various road-building materials [1]-[5]. Road construction is one of the most material-intensive industries requiring an expansion of the range of binders and road mixtures used, the main components of which can be various industrial wastes. In domestic and foreign practice of road construction, foundations and coatings made of soils and stone materials, reinforced with various slag binders, are increasingly used. Their widespread use is explained by the possibility of obtaining a slab with high deformation properties, good manufacturability and high economic efficiency associated with the economy of scarce stone materials and cement.

\footnotetext{
* Corresponding author.

E-mail address: shmaks_87@mail.ru
} 
Phosphorus granular slags, which are a local material and have astringent properties under certain conditions [6], can serve to expand the use of fortified local stone materials in the construction of road pavements in Kazakhstan.

A promising direction for the use of man-made waste of phosphorus industries (phosphogypsum, electrothermophosphoric slag, internal overburden) is their use in the construction of highways. Dump slags and mineral powder from steel-making slags are successfully used in the preparation of asphalt concrete for the upper layers of road pavements. Asphalt concrete pavements with slag aggregate are characterized by high strength, abrasion resistance, high coefficient of adhesion, and absence of shear deformations [7].

In the study, it was found that electrothermophosphoric slag, dump phosphogypsum and overburden of coal mining can be used as components for box-type pavement [8].

In road construction, ash and slag mixtures are used in the construction of subgrade, for the construction of reinforced foundations, as a filler and mineral powder in asphalt concrete. High-quality mineral powder is obtained from steel-making slag, which is an important structure-forming filler for asphalt concrete [9].

Granulated slag in road construction can be used as:

- Sandy material in the preparation of asphalt and cement-concrete mixtures, as well as for underlying layers of bases (without processing and without adding additives);

- Monolithic base under an asphalt concrete pavement (with the addition of small doses of cement, clinker dust or alkaline additives);

- When reconstructing asphalt concrete pavements and crushed stone bases (with the addition of small doses of cement or clinker dust);

- Slag binder for obtaining monolithic concrete coatings and bases (after additional processing - fine grinding together with small doses of activators: cement, lime, clinker dust);

- Subgrade with the addition of a small amount of cement, clinker dust and phosphogypsum [10].

Granulated blast-furnace slags are mainly consumed in the production of orgland slag cement, but they are also used to a significant extent as aggregate for concrete. When comparing two options for road pavements based on the use of metallurgical slag and sand-gravel mixture, it can be seen that the structure with the use of slag is not inferior to the sand-gravel surface in terms of strength characteristics, and from an economic point of view it is the most profitable and expedient, since the cost of slag is much less than the cost of gravel [11]

In work [12], many different types of raw materials were studied for the production of alkali-activated cements. However, considerable efforts have been focused on the disposal of crushed granular blast furnace slag (GBFS) from the iron and steel industry, as it is well known that alkali-activated cements obtained from this by-product can develop a microstructure comparable (in many respects) to that of a mixed portland cement.

Secondary catching cement dust - cement plant waste - has an activating ability. The rationality of using cement dust as an activator of phosphorus granular slags is determined not only by the fact that it contains various alkaline components, but also by the fact that, being an inadequate material, it is located in the area of the slag dumps.

The analysis of the raw materials used and the climatic characteristics of the study area (the fifth climatic zone) makes it possible to draw conclusions about the possibility of using waste from the phosphorus industry in road construction [13]-[16]. 
Of great practical importance for increasing the pace of road construction are not only issues related to the economic efficiency of the use of slag-mineral materials, but also issues related to the extension of the road construction season.

The purpose of the research robot is to involve waste from the phosphorus industry in the raw material base of road building materials.

The main task is to study the possibility of using slag-mineral mixtures in the year-round construction of highways.

\section{Methods ANd Methodology}

The suitability of man-made raw waste for use in road construction is established on the basis of a comprehensive study of their composition, physicochemical, mineralogical and toxicological properties. Waste sampled from dumps of enterprises was examined. The volumes of man-made waste in the dumps are: GPS - granular phosphorus slag NDFZ (Novodzhambul phosphoric plant) - 10-12 million tons; Phosphogypsum - stale, dumps of the MU (Mineral Fertilizers) plant -8.5 million tons; Overburden $\sim 20$ million tons.

During the monitoring, the following was carried out:

1. Field work:

- To map and clarify the boundaries of phosphogypsum dumps and granulated slag;

- Sampling in this area;

2. Laboratory studies of the chemical and phase composition of waste, as well as some of its physical and mechanical properties.

Samples are taken in two ways from different points of the dump:

1. From the surface of the heaps;

2. From compacted soil.

When taking samples from the surface of the heaps, a special measuring device is used. When sampling from the compacted soil on the dump and along its slopes, a hand drill is used, the depth of penetration is from $1.0 \mathrm{~m}$ to $1.5 \mathrm{~m}$. At the same time, an integral waste sample is also taken at each point.

The quantitative chemical analysis of granulated slag, phosphogypsum and overburden was carried out according to standard methods using gravimetric, spectrophotometric, potentiometric, complexometric, titrimetric methods of analysis.

The mineralogical composition of the waste was investigated according to the data of Xray structural analysis performed on a computerized diffractometer of DRON class in Co-K $\alpha$ radiation.

For all considered wastes, a study of radioactivity was carried out according to the 'Methods for measuring the activity of radionuclides' using a scintillation gamma spectrometer 'Progress-BG'.

The study of the chemical composition of the granulated slag and the analysis of the results obtained showed that when sampling at different times of the year and at different points, the chemical composition of the granulated slag does not change, which confirms the homogeneity of the material. The content of basic oxides in the slag is within the following limits, wt. \%: $\mathrm{SiO}_{2}$ 39-43; $\mathrm{CaO} 45-51 ; \mathrm{Al}_{2} \mathrm{O}_{3} 1-3 ; \mathrm{Fe}_{2} \mathrm{O}_{3}$ 0.4-0.5; $\mathrm{MgO} 2-4 ; \mathrm{SO}_{3} 0.1-1$; $\mathrm{P}_{2} \mathrm{O}_{5} 1-3 ;$ F 2-3.

The compositions of the studied samples of granulated slag comply with the requirements of the normative document ST RK 935-92 'Electrothermophosphoric granulated slags for the production of cements': $\mathrm{SiO}_{2}$ content is not less than 38 wt. \%, the sum of basic oxides $\mathrm{CaO}$ and $\mathrm{MgO}$ is not less than 43 wt. $\%, \mathrm{P}_{2} 0_{5}$ not more than 2.5 wt. $\%$. 
The presence of oxides $\mathrm{CaO}(\mathrm{C}), \mathrm{SiO}_{2}(\mathrm{~S}), \mathrm{Al}_{2} \mathrm{O}_{3}(\mathrm{~A})$ in a certain ratio determines the hydration properties of raw materials that can be used as cementitious road mixtures. The presence in slags of minerals with hydraulic activity $\left(\mathrm{C}_{3} \mathrm{~S}, \mathrm{C}_{2} \mathrm{~S}, \mathrm{C}_{2} \mathrm{~F}\right.$, etc.), and their hydrates predetermines the possibility of obtaining binders from them after preliminary drying, grinding and introduction of activators. In the study of the mineralogical properties of industrial waste, X-ray diffraction analysis of samples of the initial granulated slag showed that the materials of all samples are $98 \%$ in a structural-amorphous state.

As the results of X-ray phase analysis of phosphogypsum samples, which were subjected to heat treatment in the temperature range from $170{ }^{\circ} \mathrm{C}$ to $240{ }^{\circ} \mathrm{C}$ and heating time from 2 to 4 hours, show, its dehydration and the transition of calcium sulfate dihydrate $\mathrm{CaSO}_{4} \cdot 2 \mathrm{H}_{2} \mathrm{O}$ into hemihydrate $\mathrm{CaSO}_{4} \cdot 0,5 \mathrm{H}_{2} \mathrm{O}$, i.e. the mineral gypsum transforms into the mineral bassanite.

The results of the study of the radioactivity of waste showed that the effective specific activity of all samples $(209 ; 100 ; 37 ; 39 ; 60.7 ; 45 ; 80 \mathrm{~Bq} / \mathrm{kg})$ does not exceed the level of $300 \mathrm{~Bq} / \mathrm{kg}$ established by the Sanitary Regulations 'Sanitary and Epidemiological Requirements for Ensuring Radiation Safety', approved by the Resolution of the Government of the Republic of Kazakhstan No. 202 dated 03.02.2012. On this basis, no restrictions are imposed on the use of the considered waste in economic activities, including in the production of building materials and mixtures.

\section{RESUltS AND DiSCUSSION}

\subsection{Study of the Optimal Content of the Grain Composition of Gravel-Sand Mixtures of the Zhambyl Region in the Composition of Road Mixtures (Crushed Stone, Sand-Gravel, Sand) and Structures}

In recent years, in a number of industrialized countries, the possibilities of using a variety of industrial waste, including slag, for the construction of road surfaces and foundations have been increasingly being studied. As a result of the research and experimental work, two main directions have been identified:

- Strengthening of waste with binders;

- The use of the binding properties of industrial waste.

In Kazakhstan, about $90 \%$ of motor roads with asphalt-concrete pavements have non-rigid bases made of crushed stone, gravel-crushed stone and gravel-sand mixtures of optimal composition. The use of such bases, especially on roads with heavy and heavy traffic, leads to a loss of evenness of the surface, and, consequently, to a decrease in its transport and operational performance.

When an unreinforced base is used in a non-rigid road pavement, under the action of heavy dynamic loads from passing vehicles, large stresses arise in the contact zone of individual crushed stones, which often exceed the ultimate strength of the material and cause destruction of crushed stone grains. Such a foundation cannot be stable for a long time.

Naturally, the stability of the base will increase significantly if individual gravels are tied together, exclude the possibility of their relative movement, and turn the base into a solid slab with good bearing and distribution capacity.

For the study, gravel-sand mixtures of typical compositions for deposits in Kazakhstan, located in the $\mathrm{V}$ climatic zone, were subjected to.

The results of a survey of open pits, with the identification of the characteristics of the grain composition of gravel-sand mixtures of the Zhambyl region showed: 
- The volumetric bulk weight of the studied gravel-sand materials varies from 1.50 to $1.84 \mathrm{t} / \mathrm{m}^{3}$;

- Specific gravity - from 2.65 to $2.84 \mathrm{~g} / \mathrm{cm}$.

In terms of strength (wear in a shelf drum), samples of gravel-sand materials belong to I and II grades. In terms of frost resistance, the studied mixtures have losses within 3-4\%. The content of poorly soluble salts in the dusty fraction does not exceed $0.2 \%$.

\subsection{Research of the Technology of Road Construction from Slag-Mineral Materials in Winter}

Freezing of slag mineral material at an early age negatively affects its structure due to the passage of destructive processes, which reduces the strength of the material during its further hardening under normal conditions. Large structural disturbances occur at low negative temperatures up to $-5^{\circ} \mathrm{C}$ due to more favourable conditions for moisture migration during slow freezing of the slag-mineral material, as well as at temperatures below $-15^{\circ} \mathrm{C}$, due to the rapid freezing of the bulk of moisture in the entire volume of the material. Freezing of slag mineral material with a small amount of binder (10-15\%) in the composition leads to large losses of strength (25-40\%). With an increase in the amount of binder over $15 \%$, the negative effect of early freezing on the strength of slag-mineral materials containing more than $35 \%$ of particles larger than $5 \mathrm{~mm}$ dies out. Consequently, such compositions of slagmineral materials can be used in winter conditions of construction with freezing immediately after laying.

When arranging layers of road pavements in winter conditions, it is possible to change the temperature regime of the hardening of the layer with the transition through $0{ }^{\circ} \mathrm{C}$ immediately after its compaction, especially characteristic of the climatic conditions of the $\mathrm{V}$ road zone. When studying the effect of alternating changes in the hardening temperature of the slag binder, it was found that such conditions intensify the process of strength gain. Therefore, it could be assumed that alternating freezing and thawing will also accelerate the hardening process of slag-mineral materials.

The study of the effect of alternating freezing and thawing on the strength properties of the slag-mineral material was carried out taking into account the preservation of the optimal moisture content in the samples, at which they were pressed. This condition was adopted because the optimum moisture and density are the most favourable for hardening hardened soils. Samples - cylinders with a diameter and height of $100 \mathrm{~mm}$ were formed from slagmineral materials of various compositions. In this case, gravel-sand mixtures of three grain compositions were used with a content of particles larger than $5 \mathrm{~mm}$ in the amount of 30,50 and $70 \%$. The amount of binder in the mixture was varied from 10 to $30 \%$ with an interval of $5 \%$. To eliminate moisture loss during the first period of freezing and thawing, the samples were wrapped in a polyethylene film. Freezing was carried out at a temperature of $-5{ }^{\circ} \mathrm{C}$, which is most typical for transition periods (autumn-winter, winter-spring). Thawing was carried out in baths with a hydraulic seal for at least 4 hours. The freshly formed samples were immediately placed in a refrigerator, and then defrosted during the day and frozen again at night, considering the approach to the real temperature regime of the pavement.

For the $\mathrm{V}$ road-climatic zone, the number of air temperature transitions through $0{ }^{\circ} \mathrm{C}$ does not exceed 80-90, therefore, the number of freezing-thawing cycles was taken to a maximum of 90, considering the holding of samples for 90 days (one cycle per day). Testing of one part of the samples was carried out after 90 freeze-thaw cycles, and the other after additional incubation for 90 days under normal conditions. 
Thus, the above results showed that with alternating freezing-thawing of slag-mineral materials immediately after their compaction, their strength properties decrease due to destruction when the material contains $10 \%$ binder and when using fine-grained compositions (particles larger than $5 \mathrm{~mm}=30 \%$ ) ... With an increase in the amount of binder to $15-30 \%$ and when the content of particles larger than $5 \mathrm{~mm}$ in the composition of the slag-mineral material is more than $50 \%$, the strength of the material relative to the strength of samples of normal hardening increases by $5-30 \%$.

\subsection{Technological Features of the Preparation of Road Mixtures}

The technology of road construction, in particular of road structures, consists of the construction of the roadbed and then road pavements. Due to the long-term hardening of slowhardening cements (90 days), maintenance work, ensuring the hardening of slag-mineral materials, is replaced by the device of the upper layers of pavements. Phosphogypsum was used as a regulator and acceleration of hardening in the composition of slag-mineral mixtures, therefore its use is not considered separately. When using slow-hardening slag-mineral binders, they may have some peculiarities in technological modes associated with the setting and hardening times of the binders used. Technologies for arranging the working layer of the subgrade and layers of road pavements using slow-hardening slag cements consist of the following main technological operations:

- preparation of concrete and soil-concrete rigid road mixes in modern mechanized mixers;

- laying of rigid road mixtures by mobile pavers of monolithic layers of road pavements and the working layer of the subgrade and compaction of the layers by compaction by pneumatic rollers to the required density;

- Carrying out work on the maintenance of the hardening of layers, due to the long hardening of slow-hardening cements (90 days), is replaced by the device of the upper layers of road pavements.

The grain size composition of the materials used (stone materials or soils) also affects the technological regimes. For the construction of road pavements, stone materials are used, and for the construction of the roadbed, various finely dispersed soils. When binders are used, the top of the subgrade is usually strengthened, called the working subgrade. At present, various mechanized stationary and mobile mixers are used to prepare road mixtures for the construction of pavement and the working layer of the subgrade. The quality of road mixes depends, first of all, on the uniformity of cement distribution and the homogeneity of the components in road mixes. To study the dependence of the quality of the final product on the type of mixing of road mixtures, in the preparation of various mixtures, forced mixing mixers were used, as the most common in the road industry of Kazakhstan.

The optimality of the selected technological parameters for the preparation of the processed materials was evaluated by the physical and mechanical parameters of the obtained material. Research on the development of the technology for the preparation of hard road mixtures was carried out by their preparation in laboratory mixers for forced mixing with the addition of surfactants. Sulfite yeast mash (SYM) was used as a surfactant.

To reduce the volume of experiments and obtain more reliable information, the studies were carried out using the method of mathematical planning of the experiment [17]-[20] as the most effective for solving recipe-technological problems.

In a two-factor experiment (mixing time of the mixture $-X_{1}$ and the amount of SYM $-X_{2}$ ), it is necessary to obtain the value $Y$ - a response that depends on two variable factors $X_{1}$ and $X_{2}$, i.e. $Y=\mathrm{f}\left(X_{1} X_{2}\right)$. Using the method of the full factorial experiment, we obtain the total number of points $N=13 ; N=2 k+2 K+n 0$, where $2 k$ is the number of star points in the full 
factorial experiment $(2 k=4), 2 K$ is the number of star points $(2 K=4), n 0$ is the number of central points $(n 0=5)$, and the magnitude of the stellar arm $L=1.414$.

The planning matrix was drawn up in accordance with the recommendations [21]. Since at all points of the planning matrix the same number of parallel experiments was accepted (3), the Cochran test was applied to check the homogeneity of the variance.

Checking the significance of the coefficient of the regression equation:

$$
Y=B_{0}+B_{1} X_{1}+B_{2} X_{2}+B_{1,2} X_{1} X_{2}+B_{1,2} X_{12}+B_{2,2} X_{22},
$$

performed according to the Student's criterion (t) [22], [23]. The correspondence of the obtained model to the studied phenomenon for adequacy was checked by the Fisher criterion (F) $[17]-[20]$.

The factors and values of the experimental levels as for the preparation of mixtures in a forced mixing mixer are shown in Table 1.

The experiment planning matrix, test results and calculations are shown in Table 2 for forced mixing.

After testing the hypothesis about the adequacy of the mathematical model using Fisher's F-test, at the $5 \%$ significance level and justifying the zero hypothesis of the significance of the regression coefficients using the Student's t-test, the mathematical model has the form:

- With forced stirring:

and in natural values:

$$
Y=265.8+15.1 X_{1}-36.8 X_{2}+2.75 X_{1} X_{2}-6.2 X_{12}-25.2 X_{22},
$$

$$
R_{\mathrm{nv}}=205.6-1.19 \mathrm{~V}+163 \mathrm{D}-0.005 V_{2}-572.7 D_{2}
$$

TABLE 1. FACTORS AND THEIR LEVELS OF VALUE

\begin{tabular}{ccccccccc}
\hline \multirow{2}{*}{$\begin{array}{l}\text { Index } \\
\text { factor }\end{array}$} & $\begin{array}{c}\text { Name } \\
\text { factors }\end{array}$ & $\begin{array}{c}\text { Conditional } \\
\text { designation }\end{array}$ & Variation step & \multicolumn{5}{c}{ Variation levels } \\
\cline { 6 - 10 } & $\begin{array}{c}\text { Mixing time, } \\
\text { in s }\end{array}$ & $B$ & 35 & 25.51 & 40 & 75 & 110 & 124.49 \\
$X_{1}$ & $\begin{array}{c}\text { Amount of SYM \%, of the } \\
\text { binder weight }\end{array}$ & $D$ & 0.21 & 0 & 0.09 & 0.03 & 0.51 & 0.595 \\
$X_{2}$ & & & & & & & & \\
\hline
\end{tabular}

The calculation results are shown in Table 2.

Thus, the technologies for arranging the working layer of the subgrade and layers of road pavements using slow-hardening cements based on industrial waste from the phosphorus industry consist of the following technological operations:

- Technologies for the preparation of hard water with a limited amount of water for moistening road soil-concrete and concrete mixtures in stationary or mobile installations. To increase the mobility of rigid road mixtures and further increase the strength of the monolithic working layer of the subgrade and road pavements, plasticizing additives (surfactants) are introduced;

- Technologies for laying and compaction of road concrete and soil-concrete mixtures, by pressing, in particular, rolling by rollers on pneumatic running to the required density, since inactive rigid road mixtures are used;

- The technology of performing work on the care of the hardening of layers, used when using fast-hardening traditional cements, is also not used, due to the slow and long hardening of slag-mineral materials, it is replaced by the device of the upper layers of the pavement. 
TABle 2. MATRIX FOR PlANNING EXPERIMENTS, Results of TESTS AND CALCUlations With FORCED MIXING OF ROAD MIXTURES

\begin{tabular}{|c|c|c|c|c|c|c|c|c|c|c|c|c|c|}
\hline \multirow[b]{3}{*}{ № } & \multicolumn{4}{|c|}{ Plan } & \multirow{3}{*}{$\begin{array}{l}Y=R_{\mathrm{nv}} \\
\text { actual } \\
\mathrm{kgf} / \mathrm{cm}^{2}\end{array}$} & \multirow{2}{*}{\multicolumn{7}{|c|}{ Calculated matrix }} & \multirow{3}{*}{$\begin{array}{c}Y=R_{\mathrm{nv}} \\
\text { calculated } \\
\mathrm{kgf} / \mathrm{cm}^{2}\end{array}$} \\
\hline & \multicolumn{2}{|c|}{ coded } & \multicolumn{2}{|c|}{ natural } & & & & & & & & & \\
\hline & $X_{1}$ & $X_{2}$ & $\begin{array}{c}\text { Time } \\
\text { mixing, } \\
\mathrm{s}\end{array}$ & $\begin{array}{c}\text { quantity } \\
\text { SYM, } \\
\%\end{array}$ & & $X_{0} Y$ & $X_{1} Y$ & $X_{2} Y$ & $X_{1} X_{2} Y$ & $X_{12} Y$ & $X_{22} Y$ & $Y_{2}$ & \\
\hline 1 & -1 & -1 & 40 & 0.09 & 256 & +256 & -256 & -256 & +256 & +256 & +256 & 65536 & 241 \\
\hline 2 & +1 & -1 & 110 & 0.09 & 279 & +279 & +279 & -279 & -279 & +279 & +279 & 77841 & 287 \\
\hline 3 & -1 & +1 & 40 & 0.51 & 176 & +176 & -176 & +176 & -176 & 176 & 176 & 30970 & 180 \\
\hline 4 & +1 & +1 & 110 & 0.51 & 210 & +210 & +21 & +210 & +210 & +210 & +210 & 44100 & 211 \\
\hline 5 & -1 & 0 & 25.51 & 0.3 & 235 & +235 & -332.3 & 0 & 0 & 470 & 0 & 55225 & 231 \\
\hline 6 & -1.414 & 0 & 124.49 & 0.3 & 280 & +280 & +395.9 & 0 & 0 & 560 & 0 & 78400 & 275 \\
\hline 7 & +1.414 & -1.414 & 75 & 0 & 271 & +271 & 0 & -383.2 & 0 & 0 & 542 & 73441 & 268 \\
\hline 8 & 0 & +1.414 & 75 & 0.596 & 168 & +167 & 0 & +237.6 & 0 & 0 & 336 & 28224 & 159 \\
\hline 9 & 0 & 0 & 75 & 0.3 & 266 & +266 & 0 & 0 & 0 & 0 & 0 & 70756 & 265 \\
\hline 10 & 0 & 0 & 75 & 0.3 & 251 & +251 & 0 & 0 & 0 & 0 & 0 & 63001 & 265 \\
\hline 11 & 0 & 0 & 75 & 0.3 & 258 & +258 & 0 & 0 & 0 & 0 & 0 & 66564 & 265 \\
\hline 12 & 0 & 0 & 75 & 0.3 & 270 & +270 & 0 & 0 & 0 & 0 & 0 & 72900 & 265 \\
\hline 13 & 0 & 0 & 75 & 0.3 & 284 & +284 & 0 & 0 & 0 & 0 & 0 & 807620 & 265 \\
\hline & & & & & & $(\mathrm{O} Y)$ & $(1 Y)$ & $(2 Y)$ & $(1.2 Y)$ & $(1.1 Y)$ & $(2.2 Y)$ & $(Y Y)$ & \\
\hline & & & & & & 3204 & 120.6 & -249.6 & 11 & 1961 & 1799 & 807620 & \\
\hline
\end{tabular}

\subsection{Influence of Long-Term Technological Ruptures Caused by Transportation or Other Reasons on the Strength of Road Cinder Concretes and Slag Soils for the Construction of Subgrade on Slow-Hardening Cements}

The above test results indicate the high manufacturability of road mixtures from slagmineral materials. Considering that in production conditions, emergency cases are possible with a delay in the laying of ready-made road mixtures for a long time. Research has been carried out on the influence of the duration of the technological cycle from the preparation of slag concrete and slag-ground mixtures to their laying and compaction on the strength of concrete.

From the moment of preparation to laying and compaction, slag concrete mixtures undergo changes associated with the continuously flowing hydration and hydrolysis of the binder, as well as the physicochemical processes occurring between the aggregate (sand + crushed stone, ASG) and the products of the binder hydrolysis. To check the reliability of the results of theoretical assumptions about the possibility of a longer technological gap between the preparation of the mixture and its compaction for road concretes based on slow-hardening cements from industrial wastes of the phosphorus industry (granular slag, phosphogypsum), the following studies were performed.

To study the effect of the duration of the technological process from the preparation of the mixture to the compaction on the physicomechanical parameters of cinder concretes and slag soils, rigid mixtures were prepared with mixing them with an optimal amount of water. 
The mixtures were kept under natural conditions in air at a temperature of $20-30{ }^{\circ} \mathrm{C}$ for a specified time. Then, every day (up to 8 days), one part was taken from the aged mixtures, moistened to the optimum moisture content, thoroughly mixed, and then cylinder samples with a diameter and height of $100 \mathrm{~mm}$ were prepared on a press under a load of $20 \mathrm{MPa}$, followed by their testing at the age of 90 days. The test results are shown in Fig. 1.

As can be seen from Fig. 1, preliminary curing of the mixture before laying and rolling (molding) leads to an increase in the strength indicators of soil slag concrete and slag concrete. The strength of the materials increased from $105 \%$ to $121 \%$ over the reference strength. The strength of samples made from mixtures of optimum moisture content within 1-2 hours after mixing with water was taken as the reference strength.

The test results showed that for fine-grained slag concrete, the time of preliminary holding of the mixture for 4 days in air-dry conditions does not have a negative effect on its final strength, but, on the contrary, contributes to its increase. For medium-grained slag concretes and coarse-grained slag concretes, the optimal (permissible) holding time of the mixture is 6 and 7 days, respectively. With further aging of the mixtures, respectively, for more than 4 , 6 and 7 days, there is a decrease in the strength of cinder concretes and slag soils.

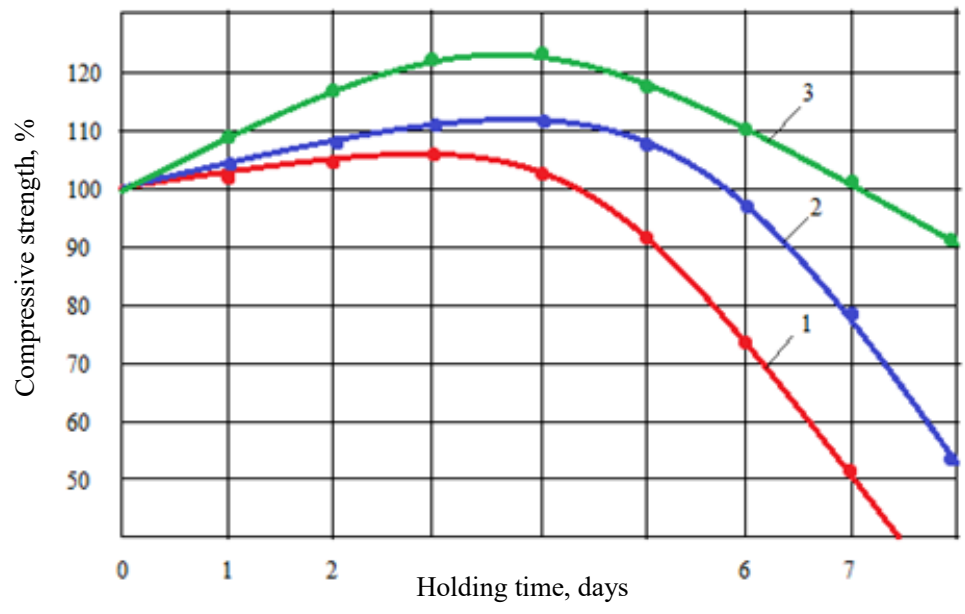

1 - fine-grained slag concrete (soil slag concrete); 2 - medium-grained slag concrete; 3 - coarse slag concrete

Fig. 1. Kinetics of the influence of the holding time of various road slag-mineral mixtures before compaction on the strength of concrete in compression.

The increase in the strength of cinder concretes and cinder soils from pre-seasoned road mixtures in natural conditions, apparently, can be explained with subsequent physicochemical processes occurring in a dispersed medium. From the moment the mixture is mixed, a thixotropic coagulation structure is first formed, followed by the creation of a denser structure on its basis. An increase in the time from mixing the mixture to mechanical action creates the conditions for even greater growth of hydrosilicate shells around the mineral shells of the binder. Mechanical action (repeated mixing and pressing) on the mixture during this period leads to rupture of the shells, with exposure of new surfaces and, accordingly, a large formation of a gel of hydrosilicate composition, which causes the observed increase in strength. 


\subsection{Technology of Compaction of Road Pavements and Working Layers of Subgrade from Slag-Minerals Based on Slow-Hardening Cements}

The ready-made slag-mineral mixtures for the arrangement of layers of road pavements or the working layer of the subgrade are transported to the construction site of the highway and unloaded with a road mixture spreader. Compaction is one of the main technological operations that determines the quality of the layer and during which the mixture is deformed in a complex way, acquiring a certain density. An increase in intergranular porosity can lead to a sharp drop in the strength of concrete, much more than that which can be caused by an increase in the porosity of the cement stone due to an increase in the water-cement ratio. In addition to decreasing strength, increasing porosity worsens frost resistance, water resistance, and hence its durability.

For clarity, Fig. 2 shows the experimental results as a relationship between the relative strength of concrete, expressed as a percentage (the strength of concrete at full compaction is taken as $100 \%$ ) and the compaction coefficient. The figure clearly shows that undercompaction of the mixture by $10 \%$ can more than halve the strength of slow-hardening road cinder concretes. Considering the great difficulty of compaction of a rigid mixture with compaction coefficients $(\mathrm{Cc})$ in the range of $0.98-1.0$, the lowest compaction coefficient value of 0.98 can be assumed.

During compaction, the total porosity of slow-hardening cinder concretes decreases, which leads to a decrease in its water saturation and a decrease in the volume of water, the freezing of which causes tensile stresses inside the material. An increase in concrete density increases its frost resistance. Fig. 3 shows the dependence of the frost resistance of slow-hardening slag concrete on the degree of its compaction.

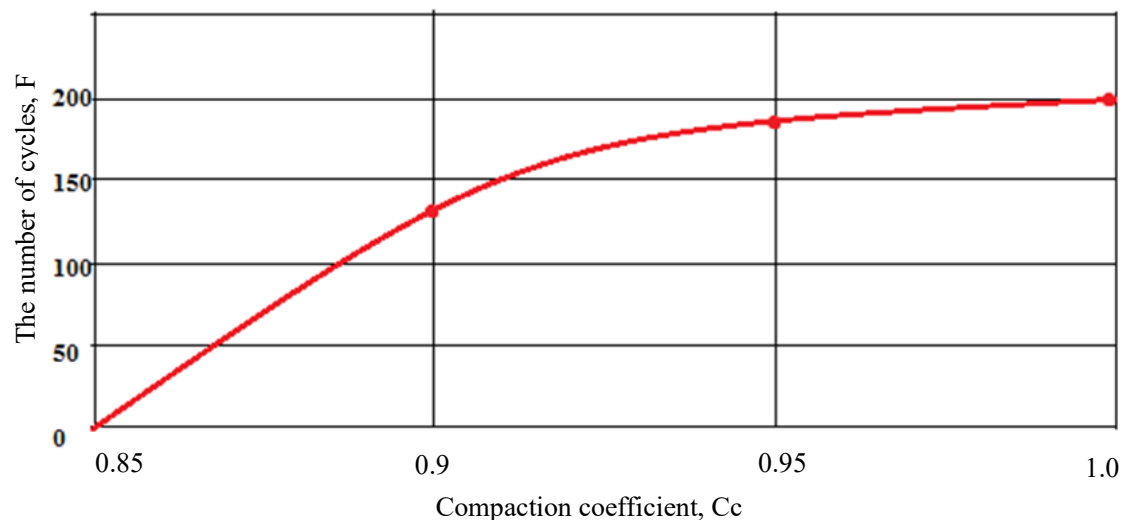

Fig. 2. Dependence of concrete strength on the degree of its compaction. 


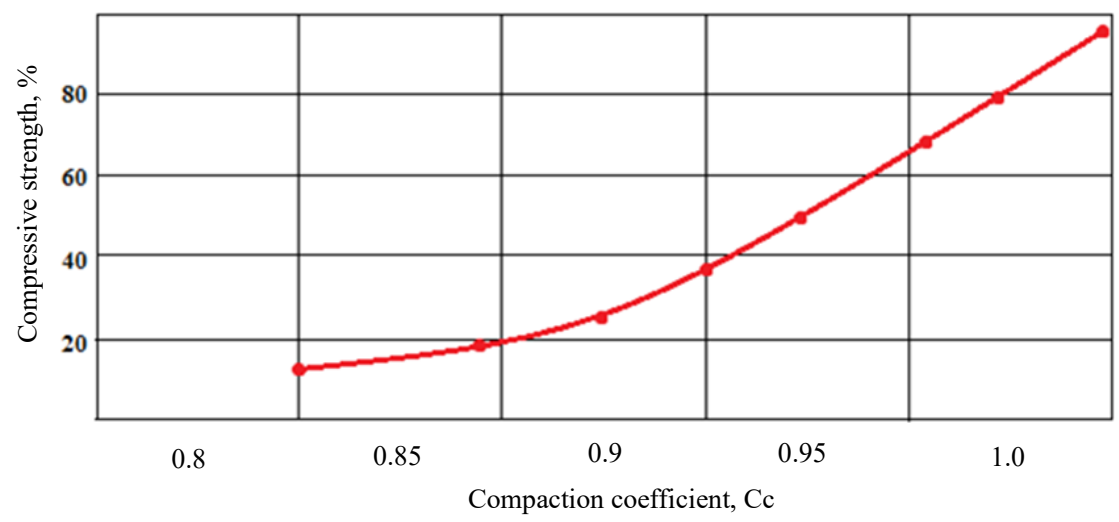

Fig. 3. Influence of the degree of compaction $(\mathrm{Cc})$ of concrete on its frost resistance $(\mathrm{F})$.

It has been established that the quality of the mixture compaction is of decisive importance to increase the frost resistance of slow-hardening concrete.

\section{ConClusion}

Based on the above results of studies of the features of the structure of the subgrade and road pavements using industrial waste (phosphorus granular slag, phosphogypsum), the following generalizing conclusions can be drawn:

1. The results of the studies carried out to study the chemical, mineralogical composition and toxicological properties of industrial waste in the Zhambyl region were the main ones for identifying the features of the technology for the construction of structural layers of road pavements using slag-mineral materials on roads of various technical categories;

2. The study of the optimal content of the grain composition of gravel-sand mixtures of the Zhambyl region in the composition of road mixtures (crushed stone, sand-gravel, sand) and structures showed that the obtained indicators of the studied gravel-sand mixtures meet the regulatory requirements. Their use in their natural form for the construction of bases or coatings is possible when strengthened with binders;

3. Studies have shown that gravel-sand mixtures, fortified with a slag binder during alternate freezing-thawing at an early age for 3 months, do not lose their properties for further hardening, since the main part of the binder is involved in this process after thawing of the material during positive temperatures. At the same time, freezing has a beneficial effect on the processes of binder hydration, which ultimately leads to the healing of the resulting partial loosening in the material and, with a sufficient amount of binder (more than $15 \%$ ), to gain strength without a decrease.

4. The best local gravel-sand materials for strengthening them with slag binder are mixtures with particles larger than $5 \mathrm{~mm}$ from 35 to $50 \%$, and with an increase in the amount of binder over $15 \%$, also mixtures with a content of such particles up to $20 \%$ and finer particles $0.05 \mathrm{~mm}$ - less than $30 \%$.

5. Research into the technology of road construction from slag-mineral materials in the winter period showed that with alternating freezing-thawing of slag-mineral materials immediately after their compaction, their strength properties decrease due to destruction when the material contains $10 \%$ binder and when using fine-grained 
compositions (particles larger than $5 \mathrm{~mm}=30 \%$ ). With an increase in the amount of binder to $15-30 \%$ and when the content of particles larger than $5 \mathrm{~mm}$ in the composition of the slag-mineral material is more than $50 \%$, the strength of the material relative to the strength of samples of normal hardening increases by 5-30\%.

6. With the elimination of partial loosening in slag-mineral materials with small additions of binder (10-15\%), during their thawing, apparently, it is also possible to achieve the strength of normal hardening. This once again confirms the possibility and expediency of using slag-mineral materials in winter construction conditions.

7. Research has established that slag-mineral materials have a sufficiently high frost resistance, which makes it possible to use this material in layers of pavements on roads of any technical category. The frost resistance of the material obtained at the age of 90 days after 15 freeze-thaw cycles is more than one, which meets the requirements of $\mathrm{CH} 25-74$ for soils strengthened with slow-hardening binders.

The use of large-tonnage man-made waste from the phosphorus industry during road construction will contribute to their widespread utilization and, as a result, reduce the cost of road construction and increase the efficiency of environmental protection, which corresponds to the priorities of the Green Economy.

\section{ACKNOWLEDGEMENT}

The main sections of the work were carried out within the framework of a scientific project 'Development of technology for the production of binders and road mixtures from the waste of the phosphorus industry' (state registration number: 0115RK01933) approved by the State Institution 'Science Committee of the Ministry of Education and Science of the Republic of Kazakhstan'.

The authors express their gratitude to the company LLP Kazakh Research and Design Institute of Road Transport Problems 'DORTRANS' for the support provided.

\section{REFERENCES}

[1] Shen W., et al. Investigation on the application of steel slag fly ash phosphogypsum solidified material as road base material. Journal of Hazardous Materials 2009:164(1):99-104. https://doi.org/10.1016/j.jhazmat.2008.07.125

[2] Wu Zh., Zhang Zh., Tao M. Stabilizing blended calcium sulfate materials for roadway base construction. Journal Construction and Building Material 2010:24(10):1861-1868. https://doi.org/10.1016/j.conbuildmat.2010.04.017

[3] Kuchma M. I., Melnik T.A. Primenenie fosfogipsa pri stroiteljstve dorozhnih odezhd (The use of phosphogypsum in the construction of road pavements.). Moscow: TsBNTI 1989:4:24-39. (in Russian)

[4] Yashin S. O., Shalnev M. N., Borisenko Yu. G. Primenenie fosfogipsa v sostave napolnitelja asfaljtobetonnih smesej (The use of phosphogypsum as a filler for asphalt concrete mixtures.). Stroitel 'nye Materialy 2009:11:18-19. (in Russian)

[5] Lyutenko A. O., Lebedev M. S. Othodi gornodobivajuschih predprijatij, kak sirje dlja proizvodstva effektivnih dorozhno-stroiteljnih materialov (Waste from mining enterprises as a raw material for the production of efficient road building materials.). Proceedings of the International scientific-practical conference 'Research, nanosystems and resource-saving technologies in the building materials industry' 2010:3:167-171. (in Russian)

[6] Gryzlov V. S., et al. Elektrotermofosfornie shlaki kak osnova vjazhuschih kompozitov (Electrothermophosphate slags as a basis for binding composites.). Stroitel 'nye Materialy 2014:10:66-69. (in Russian)

[7] Chudinov S. A. REsursosberegajuschie tehnologii stroiteljstva lesnih dorog (Resource-saving technologies for forest road construction.). Proceedings of the International Forum 'Culture and Ecology - the Basics of Sustainable Development in Russia. Cultural and Environmental Imperatives of the Modern Economy' 2020:1:50-53. (in Russian)

[8] Barkhatov V. I., et al. Othodi proizvodstv I potreblenija - rezerv stroteljnih materialov (Waste from production and consumption - a reserve of building materials.). Monograph. Chelyabinsk: CSU, 2017. (in Russian)

[9] Sofronov I. G. Stroiteljstvo avtomobiljnih dorog na osnove vtorichnih materialov (Construction of highways based on recycled materials.). International Scientific Electronic Journal: Science Online 2018:5. (in Russian) 
[10] Surankulov Sh. Zh. Stroiteljstvo dorog iz othodov himicheskoj promishlennosti (Construction of roads from chemical waste.). Proceedings of the Republican Scientific and Theoretical Conference 'Seifullin Readings-12: Youth in Science - the Innovative Potential of the Future' 2016:1(3):235-237. (in Russian)

[11] Lyshchik P. A., Naumenko A. I. Ukreplenie dorozhnih gruntov shlakovimi dobavkami (Strengthening road soils with slag additives.). Proceedings of BSTU 2012:2(149):70-72. (in Russian)

[12] Maria C., et al. Alternative inorganic binders based on alkali-activated metallurgical slags. Holmer Savastano Jr., Juliano Fiorelli, Sergio Francisco dos Santos (eds) Sustainable and Nonconventional Construction Materials using Inorganic Bonded Fiber Composites, Woodhead Publishing 2017:185-220. https://doi.org/10.1016/B978-0-08102001-2.00008-5

[13] Ismailov T. T., et al. Puti povishenija aktivnosti vjazhuschih iz othodov proizvodstva pri izgotovlenii tverdejuschih smesej dlja zakladki gornih virabotok (Ways of increasing the activity of binders from production wastes in the manufacture of hardening mixtures for laying mine workings.). Gorny information-analytical Bulletin 2009:12:180 187. (in Russian)

[14] Yashin S. O., BorisenkoYu. G. Svojstvo bitumo-mineraljnih kompozicij, modificirovannih fosfo-gipsom (Properties of bitumen-mineral compositions modified with phosphogypsum.). Magazine Building materials 2011:1:14-15. (in Russian)

[15] Martinez-Aguilar O. A., Castro-Borges P., Escalante-Garcia J. I. Hydraulic binders of Fluorgypsum Portlandcement and blast furnace slag, stability and mechanical properties. Journal Construction and Building Materials 2010:24(5):361-639. https://doi.org/10.1016/j.conbuildmat.2009.11.006

[16] Huang Yu., Lin Z. Sh. Investigation on phosphogypsum-steel slag-granulated blast-furnace slag limestone cement. Journal Construction and Building Materials 2010:24(7):1296-1301. https://doi.org/10.1016/j.conbuildmat.2009.12.006

[17] Zavadsky Yu. V. Reshenie zadach avtomobiljnogo transporta metodom imitacionnogo modelirovanija (Solving problems of road transport by the method of simulation.). Moscow: Transport, 1977. (in Russian)

[18] Zedginidze I. G. Matematicheskoe planirovanie eksperimenta dlja issledovanija I optimizacii svojstv smesej (Mathematical planning of an experiment to study and optimize the properties of mixtures.). Tbilisi: Metsnisreba, 1971. (in Russian)

[19] Metodicheskie rekomendacii po planirovaniju eksperimenta $\mathrm{v}$ tehnologii strojmaterialov (Methodical recommendations for planning an experiment in building materials technology). Sverdlovsk: UralNII Stromproekt, 1973. (in Russian)

[20] Bazhenov Yu. M., Voznesensky V. A. Perspektivi primenenija matematicheskih metodov v tehnologii sbornogo zhelezobetona (Prospects for the application of mathematical methods in the technology of precast reinforced concrete.). Moscow: Stroyizdat, 1974. (in Russian)

[21] Inozemtsev Yu. P., ShutovK. F. Betoni s povishennim rashodom zoli unosa I rolj polikondensacii v ih tverdenii (Concrete with increased consumption of fly ash and the role of polycondensation in their hardening.). Energy building abroad 1986:1:28-30. (in Russian)

[22] Quitman Erste Erfahrungen mit Walzbeton aut Wolfgang. (Quitman First experiences with rolled concrete by Wolfgang.). Strasse und Autobahn 1987:38:417-421. (in German)

[23] Walzen Verdichten der beton UDJ (Rollers compacting the concrete). Nachr 1987:47:35. (in German) 